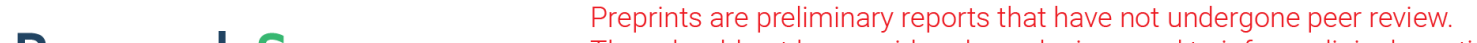 \\ They should not be considered conclusive, used to inform clinical practice, or referenced by the media as validated information. \\ Influence of Operating Parameters on the Performance of an Adsorption Solar Refrigeration Machine
}

adnane ghrici ( $\sim$ adnane.onlytheone@gmail.com )

ETAP Laboratory, Department of Mechanical Engineering, Faculty of Technology, University of Tlemcen, Algeria.

\section{MEA GHERNAOUT}

ETAP Laboratory, Department of Mechanical Engineering, Faculty of Technology, University of Tlemcen, Algeria.

\section{Mohammed BENRAMDANE}

ETAP Laboratory, Department of Mechanical Engineering, Faculty of Technology, University of Tlemcen, Algeria.

\section{Research Article}

Keywords: Refrigeration machines, adsorption, solar cooling, AC / methanol, zeolite / water and COP

Posted Date: May 12th, 2021

DOI: https://doi.org/10.21203/rs.3.rs-493114/v1

License: (c) (1) This work is licensed under a Creative Commons Attribution 4.0 International License. Read Full License 


\title{
Influence of operating parameters on the performance of an adsorption solar refrigeration machine
}

\author{
GHRICI adenane, BENRAMDANE Mohammed, GHERNAOUT MEA
}

ETAP Laboratory, Department of Mechanical Engineering, Faculty of Technology, University of Tlemcen, Algeria.

\begin{abstract}
Renewable energies including solar energy requirements for refrigeration and air conditioning are increasingly gaining interest due to the refrigerants friendly to the environment. However, it was found that these technologies have some limitations like the low performance and their high cost. This paper proposes a comparative study of a solar adsorption refrigeration machine. The study consists in determining the optimal thermodynamic parameters of operation as well as their influences on the performance of the system. This is based on a thermodynamic model using different types of adsorbent / adsorbate pairs. The main parameters considered in this study are: temperature of generation, evaporation, maximum heating temperature, condensation pressure as well as the type of the pair used: activated carbon / methanol and zeolite / water. Simulations for different thermodynamic parameters show that the COP is very sensitive to the generation and evaporation temperatures as well as the maximum heating temperature, on the other hand it was slightly influenced by the condensation pressure. The results obtained have shown that the AC / methanol pair is more profitable than the zeolite / water pair.
\end{abstract}

\section{Keywords:}

Refrigeration machines, adsorption, solar cooling, AC / methanol, zeolite / water and COP.

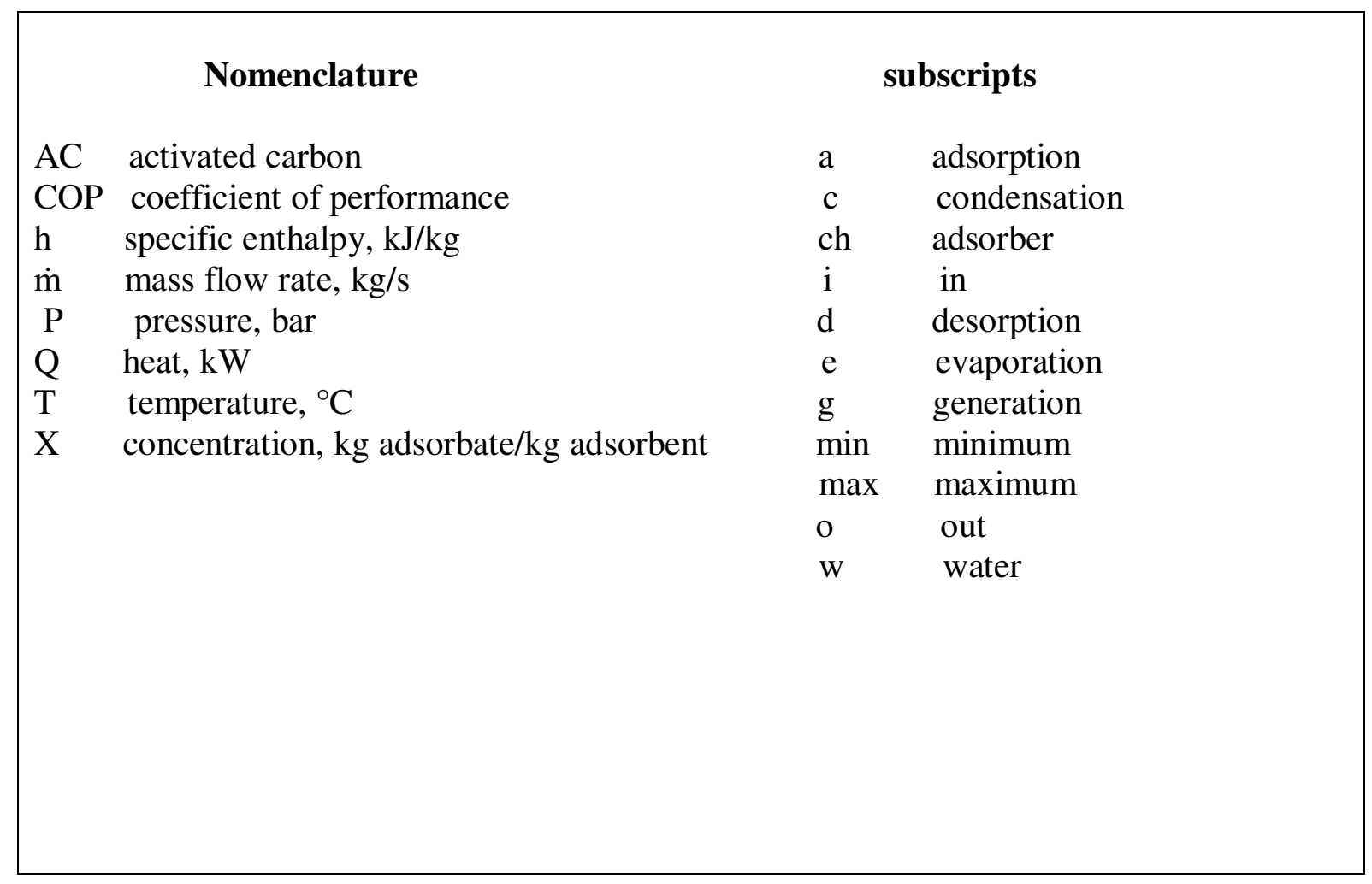




\section{Introduction}

Energy demand and growing global economic development impose challenges regarding energy supply, this is accompanied by the depletion of conventional energy resources: fuel, natural gas, coal ...etc.

On the other hand, renewable energies including solar energy are considered as alternatives and which have been the subject of interest in recent years. The conversion of solar energy into cooling has become one of the major applications, this has several methods of which gas sorption is the dominant one in air conditioning and solar refrigeration [1].

Absorption $[2,3,4,5]$ and adsorption [6,7] are the technologies that have received a great deal of interest due to their refrigeration capacities in comparison with photovoltaic systems $[8,9]$ which are offered for low-capacity air conditioning applications. In this article, the study focuses on the adsorption solar system, this technology has received several attentions because of their silent behaviour and the refrigerants friendly to the environment, especially the use of solar energy since the demand of the cold coincides most of the time with the availability of solar irradiation [10]. However, several factors have been discovered and appear to be disadvantages for this type of refrigeration such as intermittent solar energy, low coefficient of performance compared to those with vapor compression cycle, poor heat transfer performance.

In this context, several research works have been carried out mainly for the optimization of adsorption solar refrigeration systems [11] by studying the effect of operating parameters on performance $[12,13,14]$. The choice of the adsorbent / adsorbate pairs appeared essential and decisive on the performance of the system $[15,16]$, depending on the climatic conditions and type of collector also type of materials used in the installation and which influences heat and mass transfer and therefore performance, which has been shown by the literature $[17,18]$.

In this paper, thermodynamic results were presented to see the effect of coefficient of performance as a function of the pressure and temperature operating parameters and compared for two pairs chosen AC / methanol and Zeolite / water and that for a solar refrigeration system at conventional adsorption. A thermodynamic model is used to calculate the performance of the system.

\section{2. system description and working principal}

The studied system is a solar adsorption refrigerator in its simplest form, the schematic diagram of which is shown in fig. 1. [19] has shown in detail the various components of a solar adsorption refrigeration system as well as the working principle. A solar adsorption refrigerator based on the basic adsorption refrigeration cycle does not require any mechanical or electrical energy, just thermal energy, and it operates intermittently according to the daily cycle. [7]

The basic cycle process of adsorption solar refrigeration systems is as follows:

1-2: Isosteric heating

2-3: Isobaric heating

3-4: Isosteric cooling

4-1: Isobaric cooling 


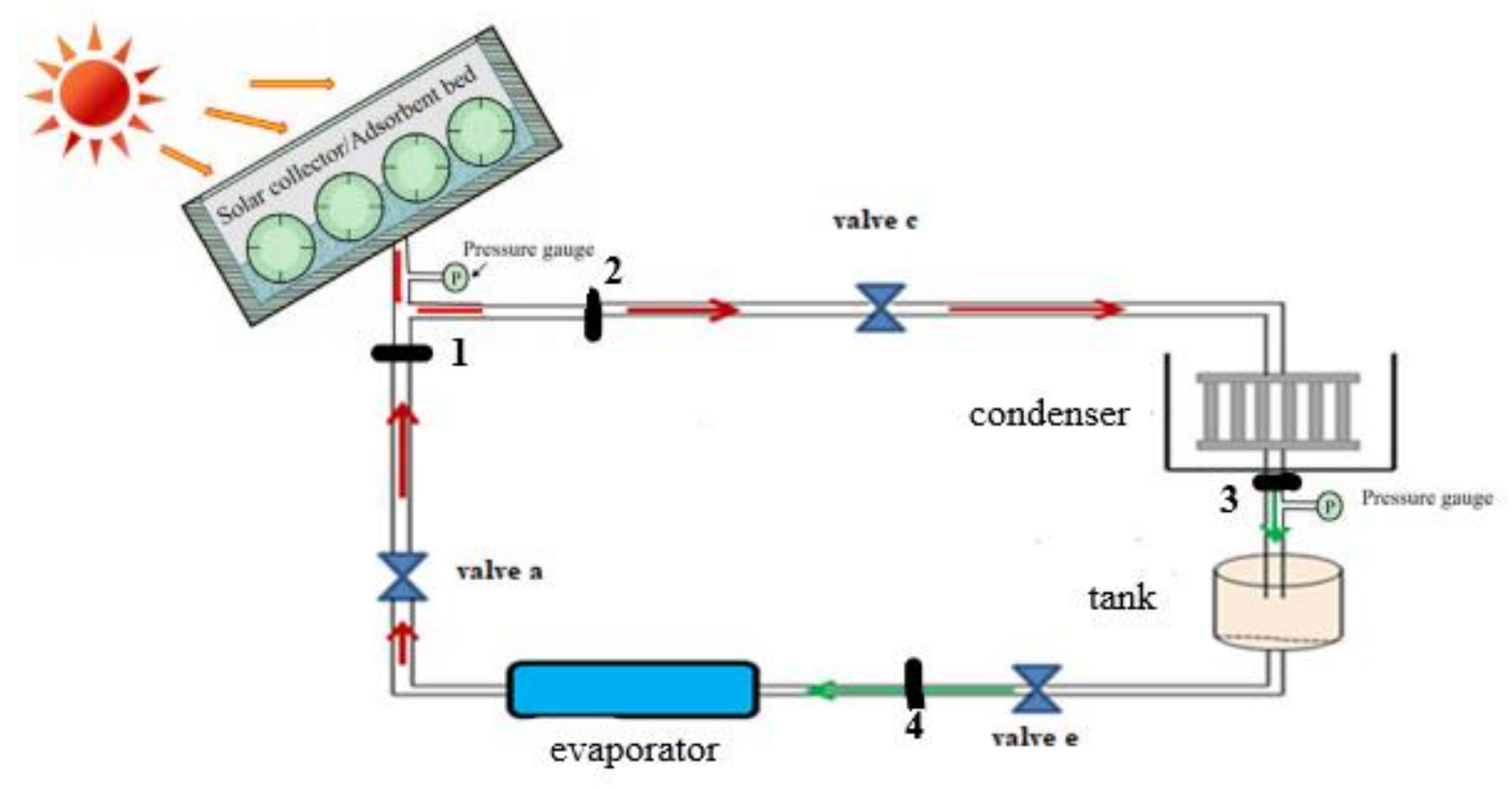

Fig. 1. Schematic diagram of the solar adsorption refrigeration system.

The cycle begins at point 1 (fig.2), when the system is at the adsorption temperature $T_{a}$ and at a low pressure $\mathrm{P}_{\mathrm{e}}$ (evaporation pressure), but the concentration of the refrigerant is maximum $\mathrm{X}_{\max }$. The adsorber receives a quantity of thermal heat $\mathrm{Q}_{\mathrm{d} 1}$ which increases the pressure and temperature along the isosteric line 1-2 (at constant concentration). at point 2, the heating continues and by increasing the temperature and desorption begins, the generation of steam occurs receiving a quantity of heat $\mathrm{Q}_{\mathrm{d} 2}$ the pressure remains constant along the isobar line 2-3 while the concentration decreases to $\mathrm{X}_{\min }$. the vapor generated is liquefied by the condenser following the isosteric line 3-4 releasing a quantity of heat $\mathrm{Q}_{\mathrm{cd}}$ at a constant concentration $\mathrm{X}_{\min }$ and at a condensing temperature Tc. During transformation 4-1, the condensed refrigerant following the isosteric line 3-4 releasing a quantity of heat $Q_{c d}$ at a constant concentration $X_{\min }$ and at a condensing temperature Tc. During transformation 4-1, the condensed refrigerant flows into the evaporator and the pressure decreases to the evaporating pressure $\mathrm{P}_{\mathrm{e}}$ and the adsorption phase occurs by absorbing a quantity of heat $Q_{e v}$ bringing the vapor back to liquid and producing the effect of cold. The evaporated refrigerant flows to the adsorber to be adsorbed and accumulated causing its concentration to increase to $X_{\max }$ at point 1 and is cooled to the adsorption temperature $\mathrm{T}_{\mathrm{a}}$ and the cycle begins again. 


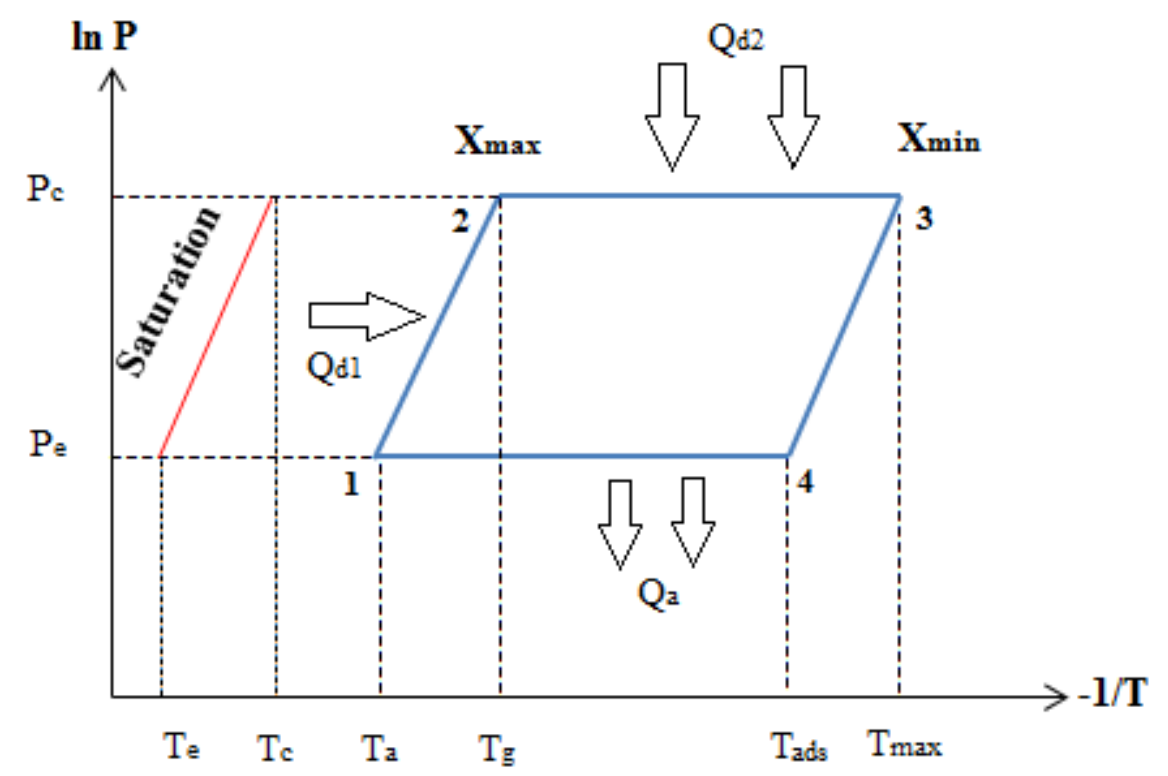

Fig. 2. Theoretical cycle of the adsorption solar refrigeration system (Clapeyron diagram)

\section{Thermodynamic study}

The refrigeration capacity, the heating capacity and the coefficient of performance are given by [20] in the equations of (1) to (3).

$$
\begin{gathered}
\mathrm{Q}_{\mathrm{e}}=\dot{\mathrm{m}}_{\mathrm{ch}} \mathrm{c}_{\mathrm{w}}\left(\mathrm{T}_{c h, i}-\mathrm{T}_{c h, o}\right) \\
\mathrm{Q}_{\mathrm{h}}=\dot{\mathrm{m}}_{\mathrm{h}} \mathrm{c}_{\mathrm{w}}\left(\mathrm{T}_{h, i}-\mathrm{T}_{h, o}\right) \\
\mathrm{COP}=\frac{\dot{\mathrm{m}}_{\mathrm{ch}} \mathrm{c}_{\mathrm{w}}\left(\mathrm{T}_{c h, i}-\mathrm{T}_{c h, o}\right)}{\dot{\mathrm{m}}_{\mathrm{h}} \mathrm{c}_{\mathrm{w}}\left(\mathrm{T}_{h, i}-\mathrm{T}_{h, o}\right)}
\end{gathered}
$$

For constant physical properties of fluids, the mass enthalpy is defined by:

$$
\Delta \mathrm{h}=c(\Delta \mathrm{T})
$$

The expression of the quantity of heat exchanged in this case by the adsorber, the condenser and the evaporator are expressed as follows:

\subsection{Adsorber / condenser}

According to the theoretical thermodynamic cycle of adsorption solar refrigeration systems, the generation of vapor from the liquid state of the working fluid occurs in two different phases:

Isosteric heating: The adsorber receives a quantity of solar energy necessary for heating the adsorbent / adsorbate pair $\mathrm{Q}_{\mathrm{d} 1}$ expressed by:

$$
\mathrm{Q}_{\mathrm{d} 1}=\dot{\mathrm{m}}_{\mathrm{d}}\left(\mathrm{h}_{2}-\mathrm{h}_{1}\right)
$$

Isobaric heating: in this phase begins the generation of steam (desorption), the required energy $\mathrm{Q}_{\mathrm{d} 2}$ is given by:

$$
\mathrm{Q}_{\mathrm{d} 2}=\dot{\mathrm{m}}_{\mathrm{c}}\left(\mathrm{h}_{3}-\mathrm{h}_{2}\right)
$$




\subsection{Evaporator}

During the evaporation phase, the refrigerant which is the adsorbate in the case of the adsorption refrigeration system, passes from the liquid state to the vapor state by absorbing a quantity of heat from the medium to be cooled $\mathrm{Q}_{\mathrm{ev}}$ corresponds to:

$$
\mathrm{Q}_{\mathrm{e}}=\dot{\mathrm{m}}_{\mathrm{e}}\left(\mathrm{h}_{1}-\mathrm{h}_{4}\right)
$$

3.3. System performance equation

The expression of the COP will be defined as follows:

$$
\mathrm{COP}=\frac{\mathrm{Q}_{\mathrm{e}}}{\mathrm{Q}_{\mathrm{g}}}
$$

Within our case $\mathrm{Q}_{\mathrm{g}}$ is given by:

$$
\mathrm{Q}_{\mathrm{g}}=\mathrm{Q}_{\mathrm{d} 1}+\mathrm{Q}_{\mathrm{d} 2}
$$

By replacing (1) and (2) in (5):

$$
\mathrm{Q}_{\mathrm{g}}=\dot{\mathrm{m}}_{\mathrm{d}}\left(\mathrm{h}_{2}-\mathrm{h}_{1}\right)+\dot{\mathrm{m}}_{\mathrm{c}}\left(\mathrm{h}_{3}-\mathrm{h}_{2}\right)
$$

The final expression of the coefficient of performance becomes:

$$
\operatorname{COP}=\frac{\dot{\mathrm{m}}_{\mathrm{e}}\left(\mathrm{h}_{1}-\mathrm{h}_{4}\right)}{\dot{\mathrm{m}}_{\mathrm{d}}\left(\mathrm{h}_{2}-\mathrm{h}_{1}\right)+\dot{\mathrm{m}}_{\mathrm{c}}\left(\mathrm{h}_{3}-\mathrm{h}_{2}\right)}
$$

\section{Working constraints}

\subsection{Hypotheses}

In order to have an agreement between the chosen model and the considered unit, certain assumptions were imposed.

- We consider that there is no heat loss to the outside environment

- All the liquid present in the adsorber is evaporated (desorption) as well as the condensate stored in the container is assumed to be completely evaporated (adsorption)

- The flow rate of the fluid in each phase is assumed to be constant

- The opening and closing of each valve are done at the end of each phase.

\subsection{Operating parameters}

- Condensation and evaporation pressure: literature shows that condensation takes place at a pressure of 145 mbar to 216 mbar, while adsorption takes place at a pressure of 90 mbar to 160 mbar [21] [22].

Our work consists in varying the pressure value in this interval to see the effect of condensing pressure on the COP and that for the two couples chosen.

- Temperatures: the operating temperatures were chosen such that they are close to those found in the experimental units seen in the literature [10] [12].

The objective of this study is to investigate the COP variation as a function of operating temperatures and pressure as well as a comparative profitability study between the two pairs chosen: AC / methanol and zeolite / water. 


\subsection{Data table}

The data required for the calculation software are presented in the following table:

\begin{tabular}{llll}
\hline Symbol & \multicolumn{1}{c}{ parameter } & \multicolumn{2}{c}{ value } \\
\hline$\dot{\mathrm{m}}_{\mathrm{c}}$ & Mass flow rate of condensate & $3.7 \mathrm{~m}^{3} / \mathrm{h}$ & {$[10]$} \\
$\dot{\mathrm{m}}_{\mathrm{d}}$ & Desorption phase mass flow & $1.6 \mathrm{~m}^{3} / \mathrm{h}$ & {$[10]$} \\
$\dot{\mathrm{m}}_{\mathrm{e}}$ & Evaporation phase mass flow & $2 \mathrm{~m}^{3} / \mathrm{h}$ & {$[10]$} \\
$\mathrm{P}_{\mathrm{c}}$ & Condensing pressure & $0.21676 \mathrm{bar}[20]$ \\
$\mathrm{P}_{\mathrm{e}}$ & Evaporation pressure & $0.02872 \mathrm{bar}[20]$ \\
$\mathrm{T}_{\mathrm{a}}$ & Adsorption temperature & $16{ }^{\circ} \mathrm{C}$ & {$[12]$} \\
$\mathrm{T}_{\mathrm{e}}$ & Evaporating temperature & $-5{ }^{\circ} \mathrm{C}$ & {$[12]$} \\
$\mathrm{T}_{\mathrm{g}}$ & Generation temperature & $61{ }^{\circ} \mathrm{C}$ & {$[12]$} \\
$\mathrm{T}_{\mathrm{max}}$ & Maximum heating temperature & $82{ }^{\circ} \mathrm{C}$ & {$[12]$} \\
\hline
\end{tabular}

Table 1. Calculation data.

\section{Results and interpretation}

To facilitate the analysis of the effect of varying the operating parameters of different components of the solar adsorption refrigeration system on performance, a thermodynamic model was presented. Numerical analysis consists of obtaining the appropriate configurations and therefore making the improvements to the COP.

The governing equations have been solved by a computer code which takes into consideration the thermodynamic adsorption cycle presented by the pressure and temperature parameters at each point of the diagram (figure 2) and from there the quantities of heat exchanged can be determined and represented as a function of the mass enthalpy at this point. So, the variation of the operating parameters which describes the cycle cause the variation in the quantity of associated heat, hence the importance of the parametric study given the great dependence between the operating parameters and the coefficient of performance given in the model thermodynamics as the ratio between the quantities of associated heat. So, this work consists in showing this dependence positively or negatively. Another factor is taken into consideration, it is the choice of the type of adsorbent / adsorbate pair. This work also aims to see the behaviour of performance under the effect of the chosen pair and to determine the best operating conditions for the pairs. In this case, AC / methanol and zeolite / water were chosen as the adsorbent / adsorbate pair.

In this study, we respectively discuss the effect of: (1) the maximum temperature $T_{\max }$ (2) the evaporation temperature $T_{e}(3)$ the generation temperature $T_{g}(4)$ the condensing pressure $P_{c}$ as well as the choice of the couple adsorbent / adsorbate on the COP. Calculation data is shown in Table 1. 


\subsection{Model validation}

The values of the coefficient of performance COP as a function of the maximum temperature reached during the heating of the adsorption bed for the $\mathrm{AC} /$ methanol couple and those calculated by douss \& meunier are presented in table.2. The figure shows a reasonable agreement between the results although the COP shows a slight difference, which can be a consequence of not taking into account the thermal losses present in each phase and the difference between the operating conditions taken in each model.

\begin{tabular}{lrrrrrr}
$\mathrm{T}_{\max }{ }^{\circ} \mathrm{C}$ & 70 & 75 & 80 & 90 & 110 & 130 \\
$\mathrm{COP}_{\text {model }}$ & 0.496 & 0.417 & 0.359 & 0.281 & 0.195 & 0.149 \\
\hline $\mathrm{COP}_{\text {douss\&meunier }}$ & 0.49 & 0.5 & 0.51 & 0.51 & 0.49 & 0.47 \\
\hline
\end{tabular}

Table 2. The COP calculated by the model and by douss \& meunier [12].

\subsection{Generation temperature effect}

The effects of the generation temperature $\mathrm{Tg}$ on the coefficient of performance are shown in fig. 3. From the figure, it is noticed that the COP increases with the increase in the generation temperature and that for the two pairs used AC / methanol and zeolite / water. The reason is that the mass of the adsorbate generated is proportional at the generation temperature, in fact, increasing the generation temperature ensures better heat transfer performance at the adsorption bed level, which gives a greater amount of adsorbed mass and subsequently an increase in COP.

In addition, it is found that the change in COP as a function of the generation temperature is clearly different in the two cases of the pair type. The COP varies rapidly with the generation temperature in the case of the $\mathrm{AC} /$ methanol pair and reaches a maximum COP of 0,45 at $\mathrm{T}_{\mathrm{g}}=$ $80{ }^{\circ} \mathrm{C}$. on the other hand, in the case of the zeolite / water pair, the COP varies slowly and reaches a maximum value of around 0,15 . 


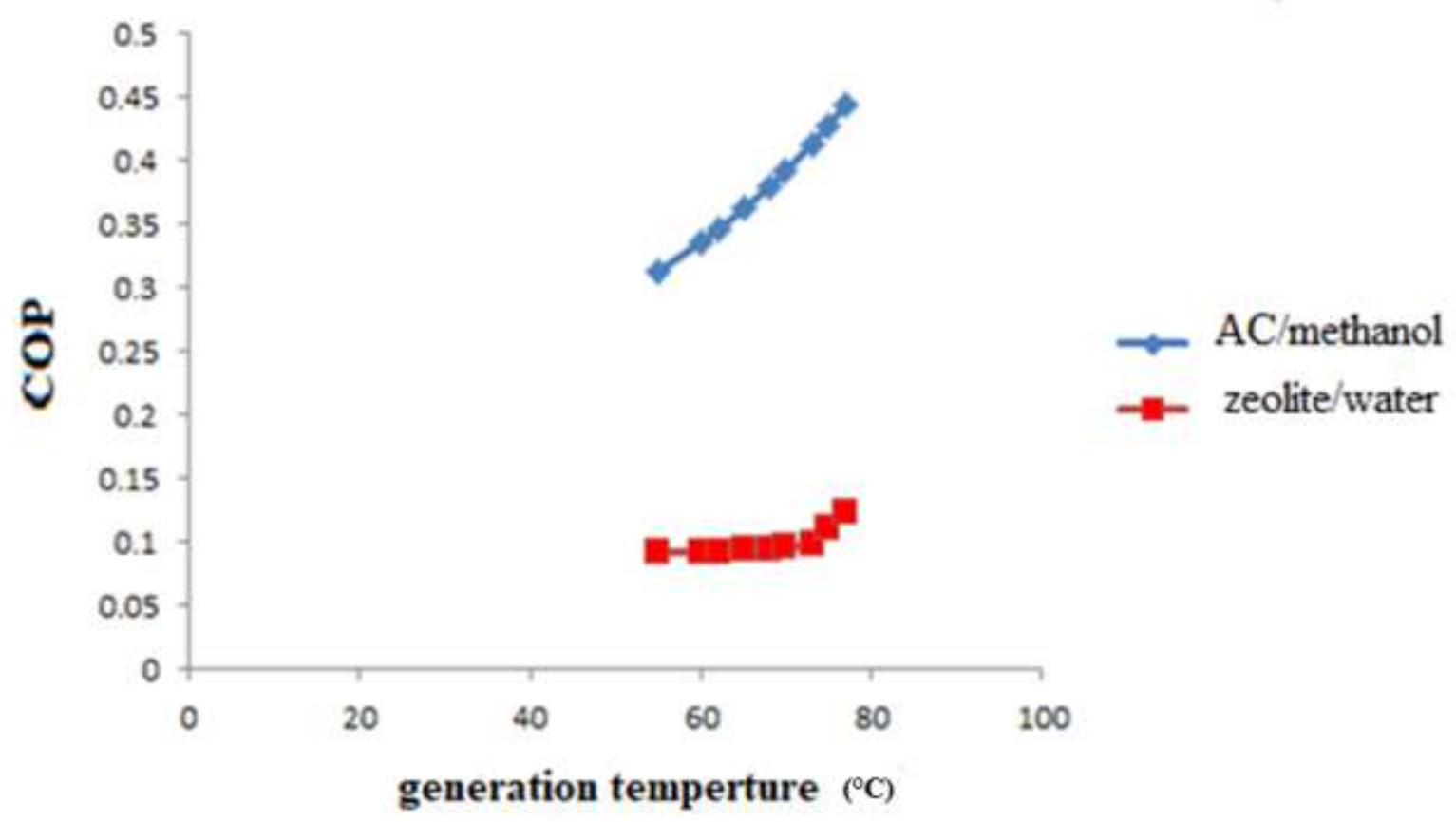

Fig. 3. Effect of the generation temperature $\mathrm{T}_{\mathrm{g}}$ and type of the pair on the COP

\subsection{Effect of evaporating temperature on the COP}

Fig. 4. shows the effect of varying the evaporating temperature $\mathrm{T}_{\mathrm{ev}}$ on the performance of the system. As can be seen in the figure, the COP decreases as the evaporating temperature increases. In addition, the COP in the case of the AC / methanol pair decreases rapidly in comparison with the zeolite / water pair. In the first case the COP reaches 0.09 at $\mathrm{T}_{\mathrm{ev}}=10{ }^{\circ} \mathrm{C}$ and 0.01 in the second case for the same temperature. The results also show that the $\mathrm{AC} /$ methanol pair is more profitable in comparison with the zeolite / water pair. In the first case the COP reaches its maximum value of 0.35 at $\mathrm{T}_{\mathrm{ev}}=-5{ }^{\circ} \mathrm{C}$ while in the other case the maximum value of COP is of the order of 0.1 for the same evaporation temperature.

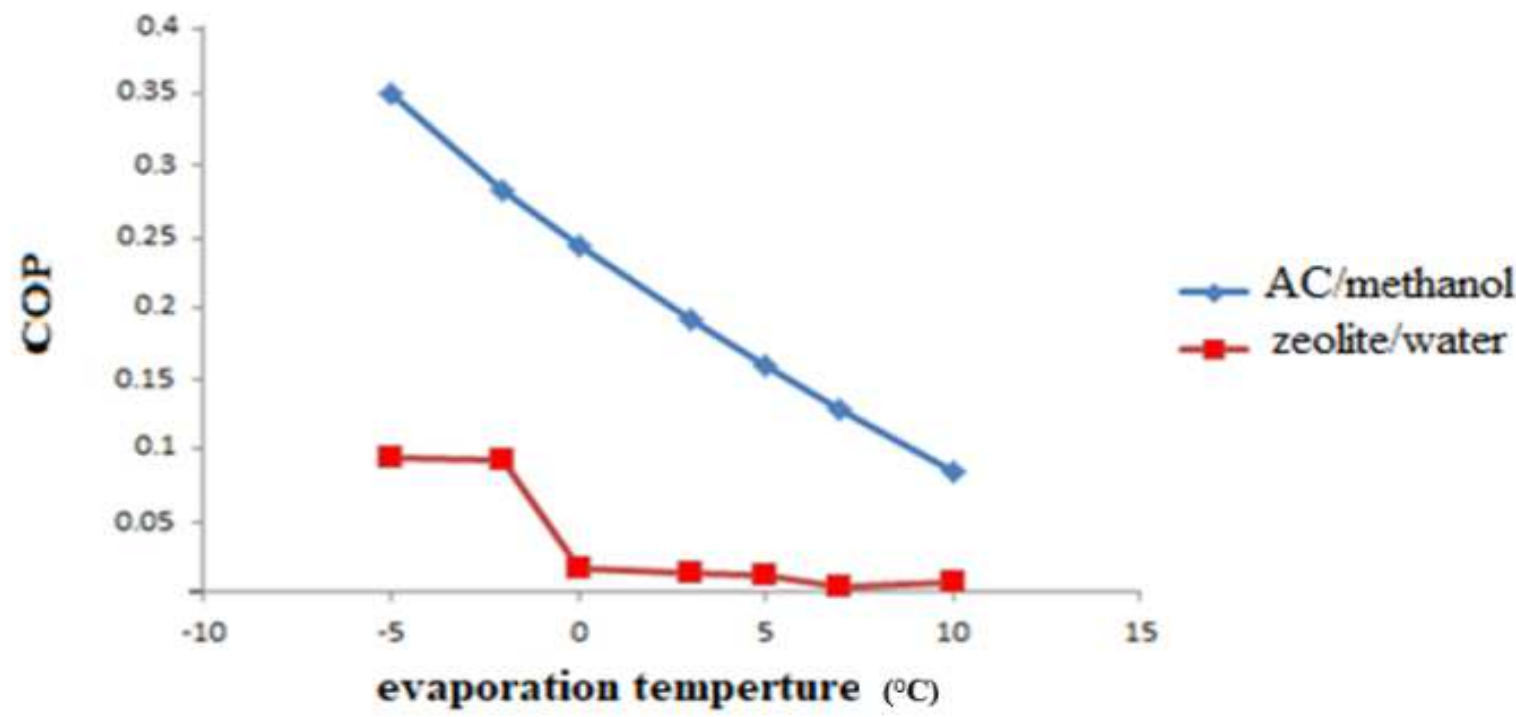

Fig. 4. COP variation as a function of the evaporation temperature $\mathrm{T}_{\mathrm{ev}}$ and type of the pair. 


\subsection{Effect of the maximum temperature on the COP}

A number of simulations have been carried out by varying the temperature of the maximum adsorption bed during the heating phase. Fig. 5 shows the results for the two types of couples used. The figure suggests that the COP decreases when the maximum heating temperature increase. the figure also shows that the optimum COP reached is 0.49 in the case of the $\mathrm{AC} /$ methanol couple for a temperature of $70{ }^{\circ} \mathrm{C}$ and 0.093 in the case of the zeolite / water couple. As with high heating temperatures, the COP decreases slower in the second case, reaching lower COPs.

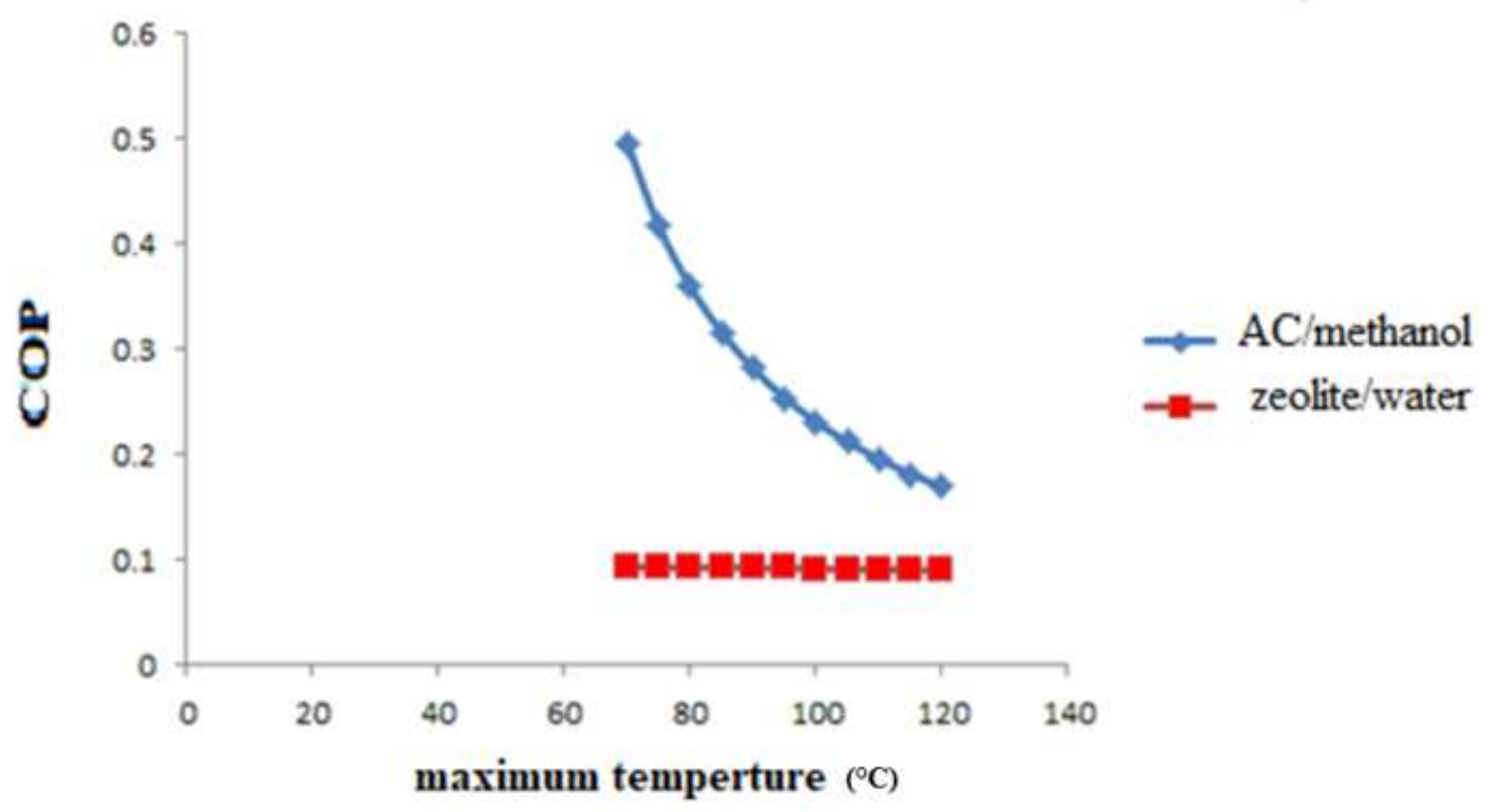

Fig.5.variation of COP with maximum temperature $\mathrm{T}_{\mathrm{g}}$ and type of the pair.

\subsection{Effect of condensing pressure}

Fig. 6 shows the variation in the effect of condensing pressure on the coefficient of performance. The results showed that the COP is slightly affected by the variation of the condensing pressure between 100 mbar and 270 mbar. This corresponds to a maximum COP of 0.346 in the case of the AC / methanol pair and 0.0972 in the case of the zeolite / water pair. Another thing can be seen in the figure is the influence of adsorbent / adsorbate pair type. This is present in this study with the use of the zeolite / water and AC / methanol pair, the latter seems to be the most favourable given the high values of COP given in each simulation under such imposed operating conditions of pressure and temperature and with this type of system and these components illustrated above. In addition, the profitability of the adsorbent / adsorbate couple can be affected by the components of the solar adsorption system used and the operating conditions and the incident solar flux. 


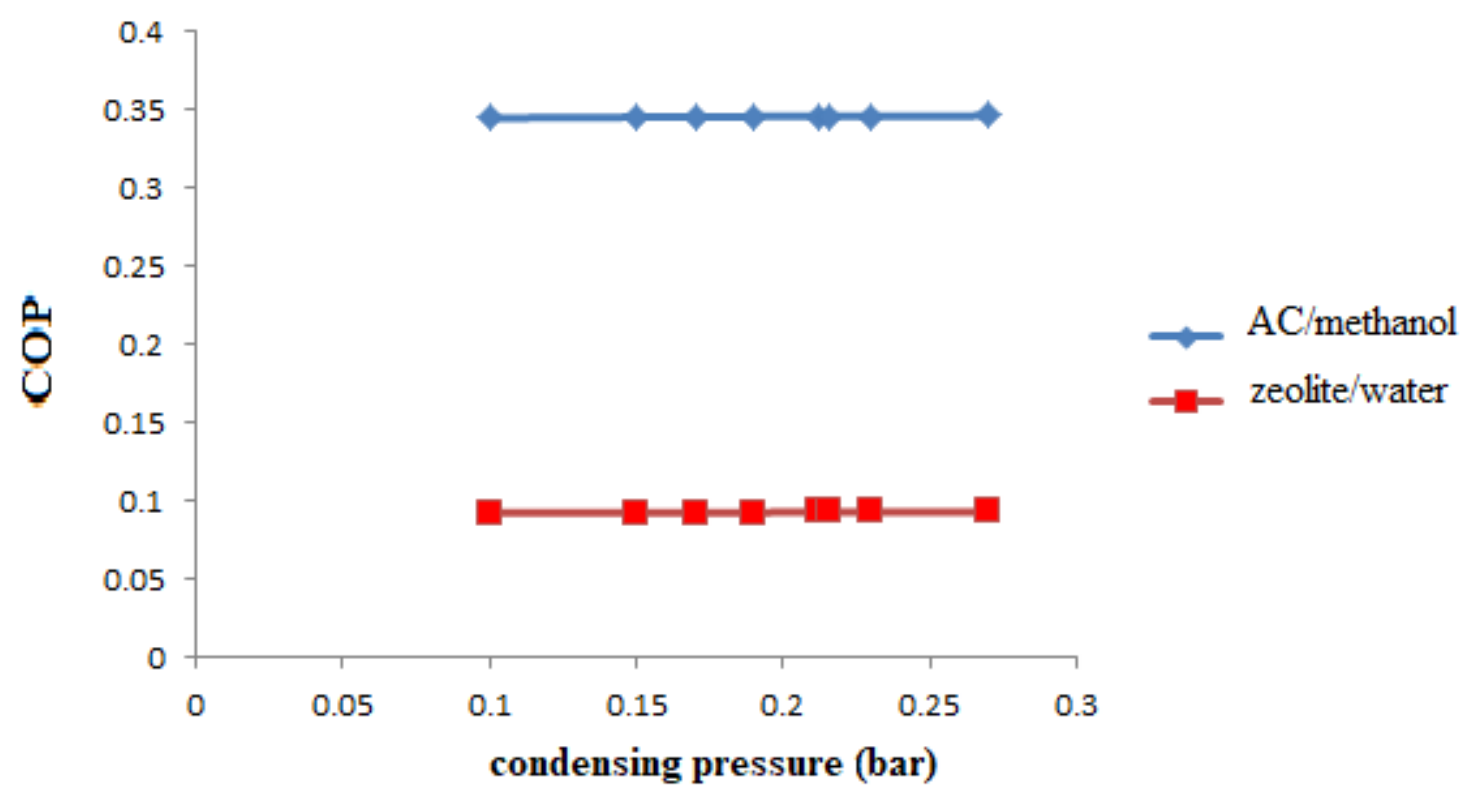

Fig. 6. Effect of condensing pressure $\mathrm{P}_{\mathrm{c}}$ and the pair type on the COP.

\section{Conclusions}

The effects of variations in the operating parameters of a refrigeration system based on $\mathrm{AC} /$ methanol and zeolite / water pairs is studied using a thermodynamic equilibrium model describing the amount of heat exchanged in each component of the solar adsorption refrigeration system.

the following conclusions can be drawn:

- The performance of the system in terms of COP varies almost linearly with the generation temperature $T_{g}$. The coefficient of performance increases remarkably if $T_{g}$ is increased.

- The COP decreases with the increase in the evaporating temperature $T_{e}$ for fixed operating parameters. A similar effect is observed when the maximum heating temperature $\mathrm{T}_{\max }$ is increased.

- The condensation pressure does not present a determining factor in this study because the COP is slightly affected by its evolution and it is observed that the two pairs used $\mathrm{AC} /$ methanol and zeolite / water give the same variation while the effect was different. which appears in a COP of 0.346 in the case of the $\mathrm{AC} /$ methanol couple and 0.0972 in the other case.

- This study has shown that a solar adsorption refrigeration machine operating with the $\mathrm{AC} /$ methanol pair is more profitable than a machine operating with the zeolite / water pair, which justifies the wide use and commercialization of this pair in this field in the face of other.

This study evaluated the direction of variation of $\mathrm{COP}$ as a function of the operating parameters with a comparison between the two pairs used in this adsorption solar refrigeration system and 
their effects on performance, which leads to an improved system with a COP comparable to values reported in the literature. These results are therefore useful for further research into performance improvements in this area and with this type of systems.

\section{References}

[1] R. BEST, N. ORTEGA, SOLAR REFRIGERATION AND COOLING, Renewable Energy 16 (1999) 685-690.

[2] A. Aliane, S. Abboudi, C. Seladji, B. Guendouz, An illustrated review on solar absorption cooling experimental studies, Renewable and Sustainable Energy Reviews 155 (2018) 253 261.

[3] Z.S. Lu, R.Z. Wang, Z.Z. Xia, X.R. Lu, C.B. Yang, Y.C. Ma, G.B. Ma, Study of a novel solar adsorption cooling system and a solar absorption cooling system with new CPC collectors, Renewable Energy 50 (2013) 299-306.

[4] Osman K. Siddiqui, Bekir S. Yilbas, Solar absorption heating in horizontal channel: Influence of absorbing plate location on thermal performance, Energy Conversion and Management 74(2013)140-148.

[5] Antonio Lecuona, Rubén Ventas, Ciro Vereda, Ricardo López, Absorption solar cooling systems using optimal driving temperatures, Applied Thermal Engineering (2015), doi: 10.1016/ j. applthermaleng.2014.10.097.

[6] A.O. Dieng, R.Z. Wang, Literature review on solar adsorption technologies for ice-making and air conditioning purposes and recent developments in solar technology, Renewable and Sustainable Energy Reviews 5 (2001) 313-342.

[7] M.S. Fernandes, G.J.V.N. Brites, J.J. Costa, A.R. Gaspar, V.A.F. Costa Review and future trends of solar adsorption refrigeration systems, Renewable and Sustainable Energy Reviews39(2014)102-123.

[8] Thomachan A. Kattakayam, K. Srinivasan, Thermal performance characterization of a photovoltaic driven domestic refrigerator, International Journal of Refrigeration 23 (2000) 190196.

[9] Y. Li, G. Zhang, G.Z. Lv, A.N. Zhang, R.Z. Wang, Performance study of a solar photovoltaic air conditioner in the hot summer and cold winter zone, Solar Energy 117(2015)167-179.

[10] N. Ghilen, S. Gabsi, S. Messai, R. Benelmir, M. El Ganaoui, Performance of silica gelwater solar adsorption cooling system, Case Studies in Thermal Engineering 8 (2016) 337345.

[11] K.C.A. Alam, B.B. Saha, A. Akisawa, T. Kashiwagi, Optimization of a solar driven adsorption refrigeration system, Energy Conversion and Management 42 (2001) 741-753.

[12] N. Douss, F. Meunier, Effect of operating temperatures on the coefficient of performance of active carbon-methanol systems, Heat Recovery Systems \& CIIP Vol. 8, No. 5, pp. 383-392, 1988.

[13] N. CHERRAD, Modélisation numérique des températures limites du cycle des machines frigorifiques solaires à adsorption, Le 5ème Séminaire International sur les Energies Nouvelles et Renouvelables, Unité de Recherche Appliquée en Energies Renouvelables, Ghardaïa - Algeria 24 - 25 Octobre 2018. 
[14] Y. Liu, K.C. Leong, the effect of operating conditions on the performance of zeolite/water adsorption cooling systems, Applied Thermal Engineering 25 (2005) 1403-1418.

[15] Khairul Habib, Bidyut Baran Saha, Shigeru Koyama, Study of various adsorbent refrigerant pairs for the application of solar driven adsorption cooling in tropical climates, Applied Thermal Engineering 72(2014)266-274.

[16] Y.M. Liu, Z.X. Yuan, X. Wen, C.X. Du, Evaluation on performance of solar adsorption cooling of silica gel and SAPO-34 zeolite, Applied Thermal Engineering 182 (2021) 116019.

[17] Nidal H. Abu-Hamdeh, Khaled A. Alnefaie, Khalid H. Almitani, Design and performance characteristics of solar adsorption refrigeration system using parabolic trough collector: Experimental and statistical optimization technique, Energy Conversion and Management 74 (2013) 162-170.

[18] Shu Xua, Simulation on a New Adsorption Bed about Adsorption Refrigeration Driven by Solar Energy, Procedia Engineering 15 (2011) 3865 - 3869.

[19] Yunfeng Wang, Ming Li, Wenping Du, Xu Ji, Lin Xu, Experimental investigation of a solar-powered adsorption refrigeration system with the enhancing desorption, Energy Conversion and Management 155(2018) 253-261.

[20] Z.S. Lu,R.Z. Wang, Z.Z. Xia, X.R. Lu, C.B. Yang, Y.C. Ma, G.B. Ma, Study of a novel solar adsorption cooling system and a solar absorption cooling system with new CPC collectors, Renewable Energy 50(2013)299-306.

[21] H. Ambarita, H. Kawai, Experimental study on solar-powered adsorption Refrigeration cycle with activated alumina and activated Carbon as adsorbent, Case Studies in Thermal Engineering7(2016)36-46.

[22] W. Chekirou, N. Boukheit, A. Karaali, Dynamic model of heat and mass transfer in rectangular adsorber of a solar adsorption machine, Journal of Physics: Conference Series 758 (2016) 012006. 
Figures

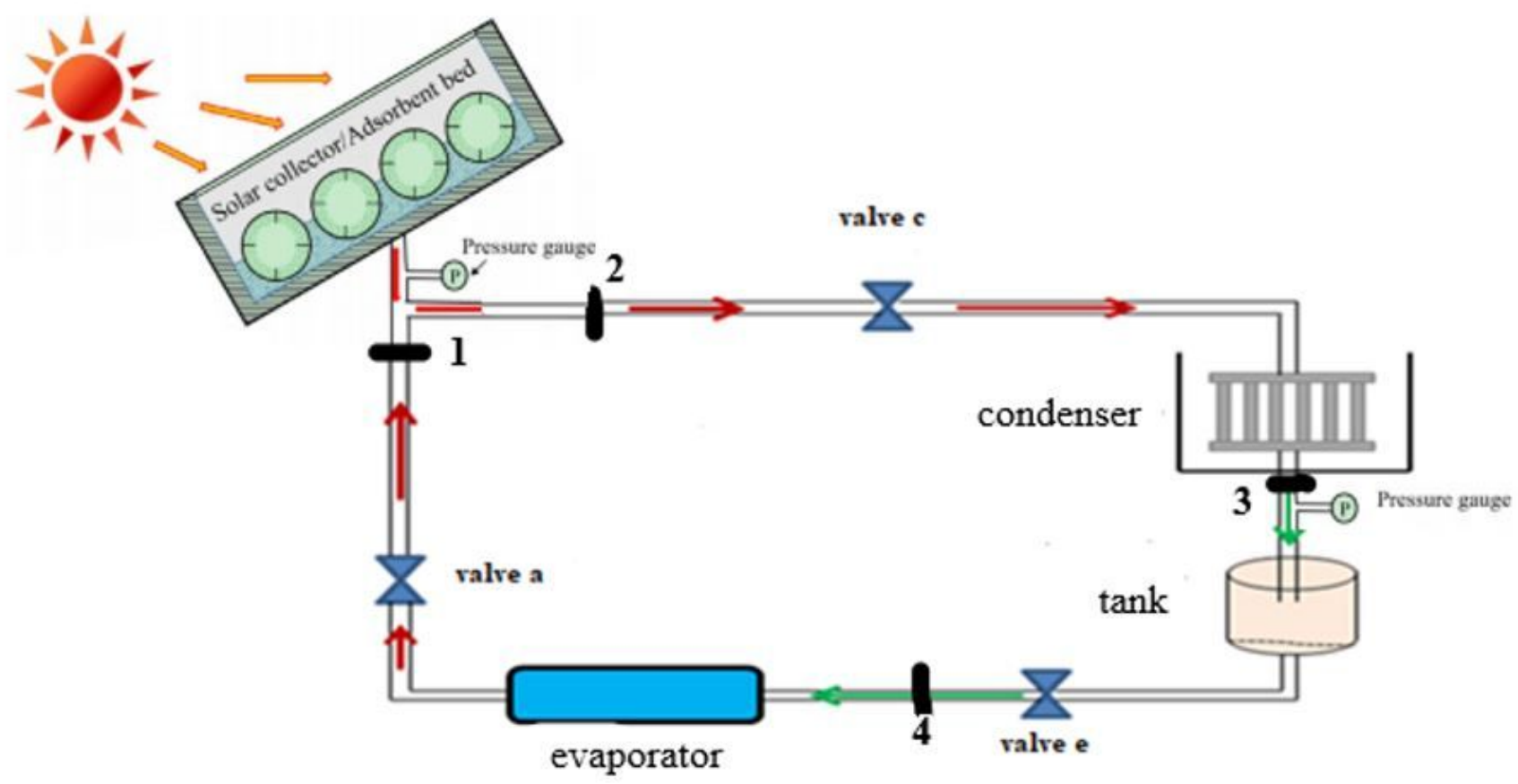

Figure 1

Schematic diagram of the solar adsorption refrigeration system. 


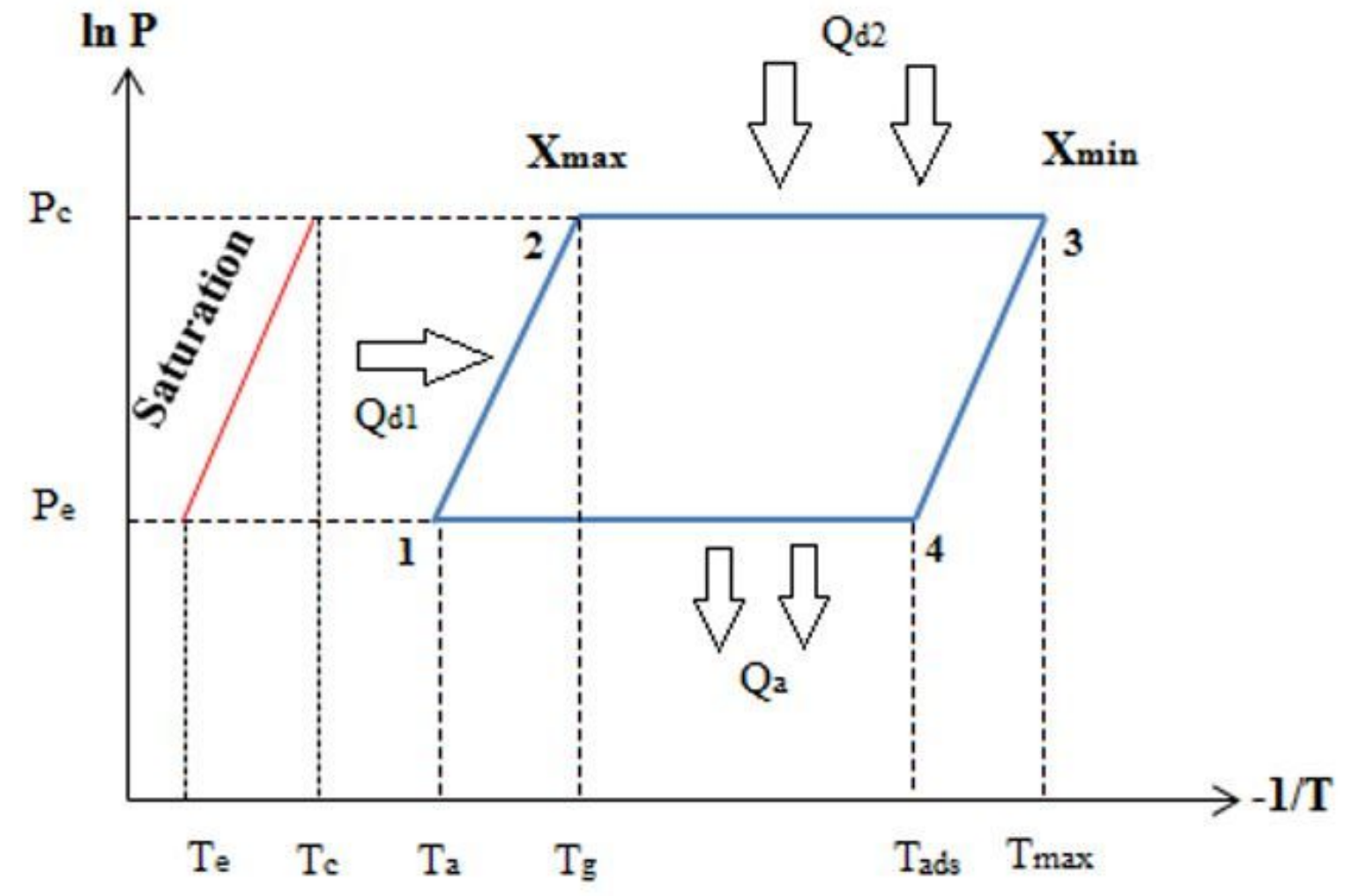

Figure 2

Theoretical cycle of the adsorption solar refrigeration system (Clapeyron diagram) 


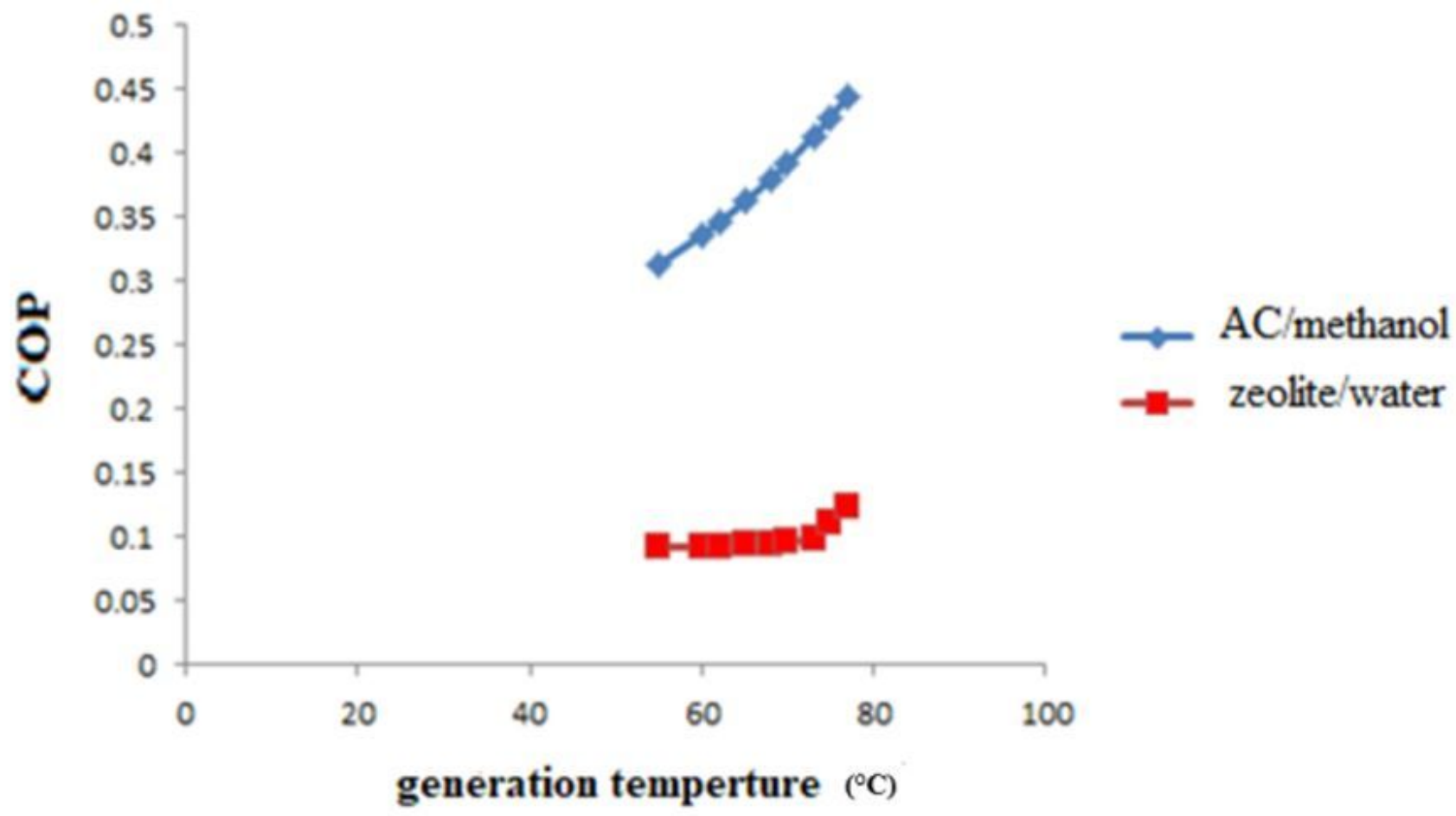

Figure 3

Effect of the generation temperature $\mathrm{Tg}$ and type of the pair on the COP

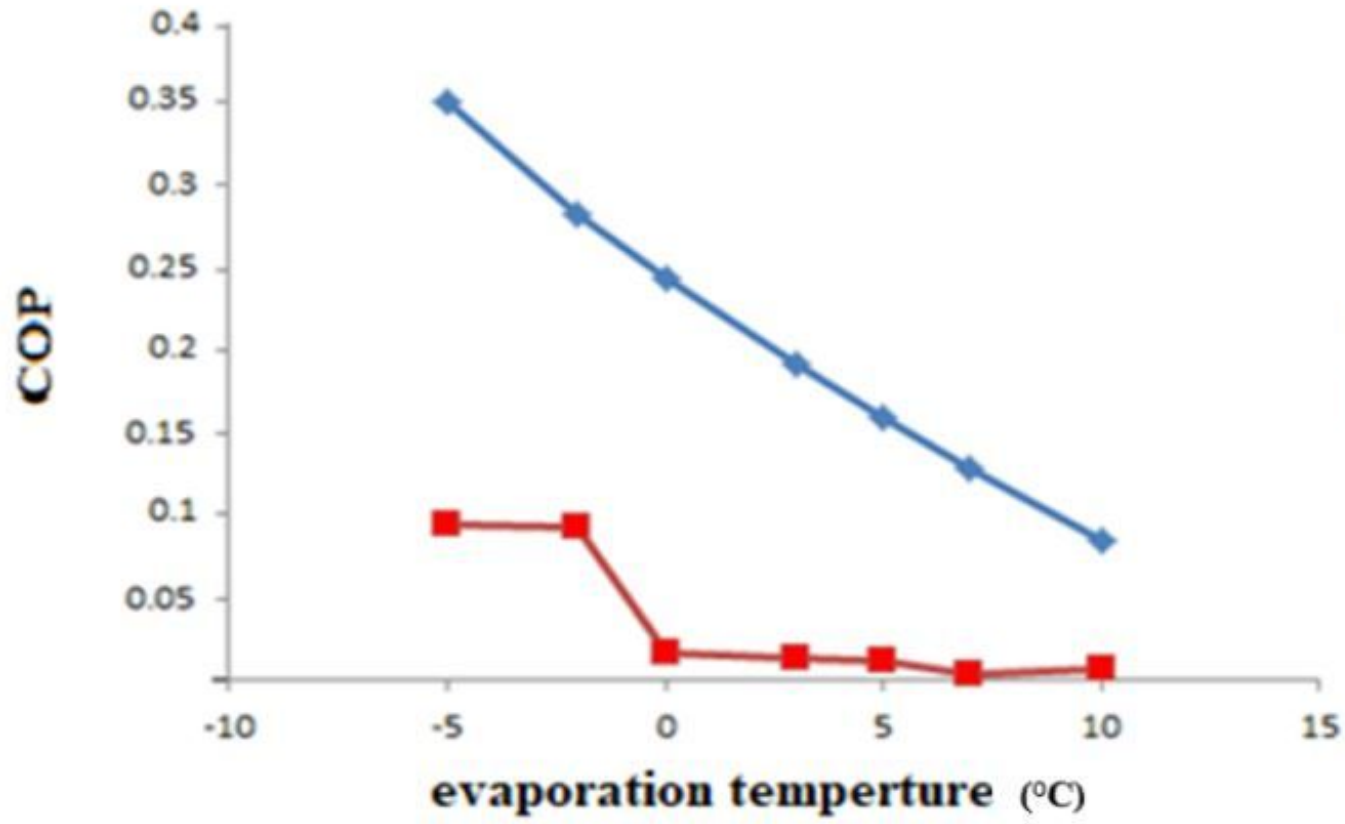

$\multimap \mathrm{AC} /$ methanol

$\rightarrow$ - zeolite/water

Figure 4

COP variation as a function of the evaporation temperature Tev and type of the pair. 


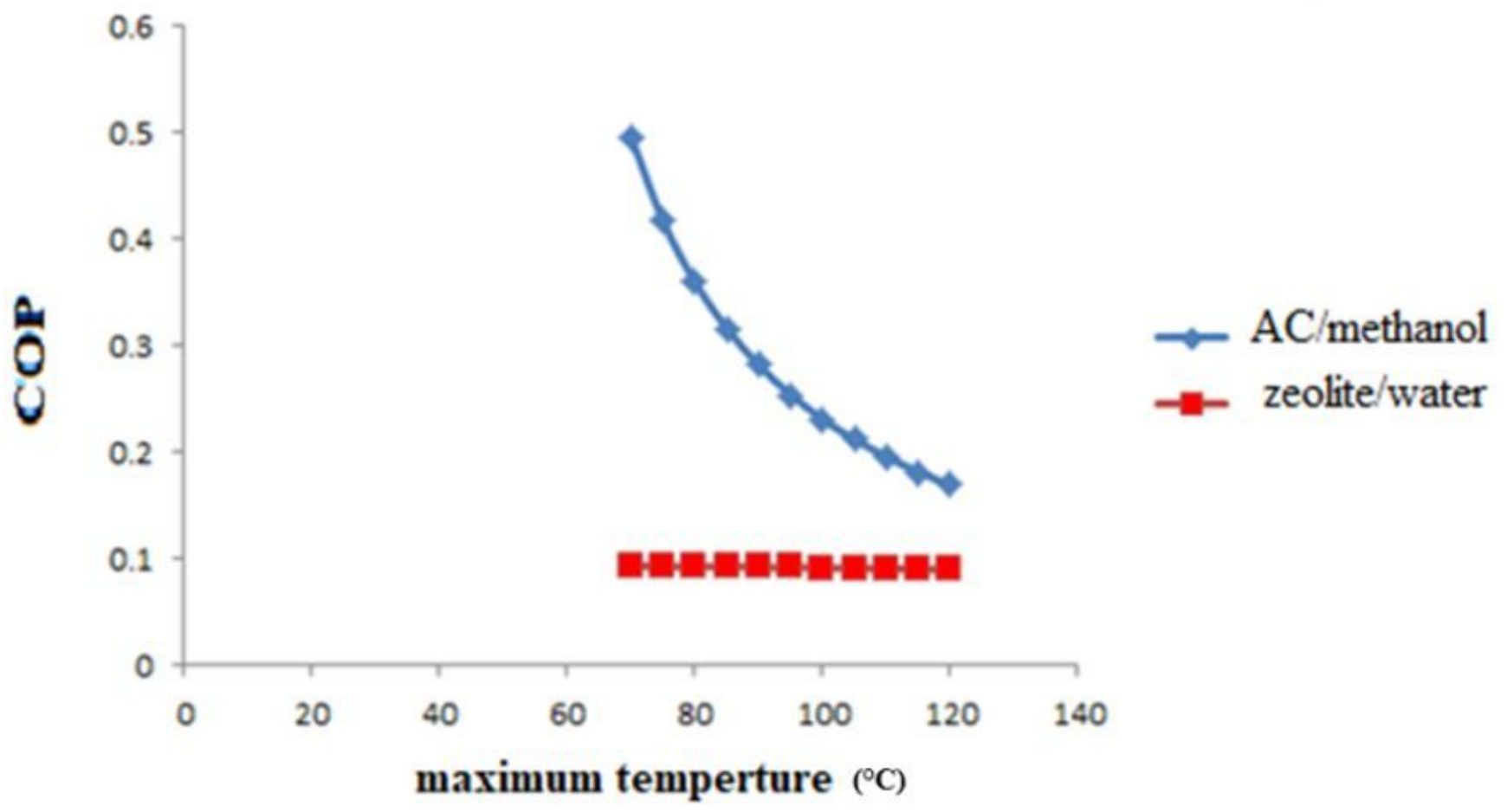

Figure 5

variation of COP with maximum temperature $\mathrm{Tg}$ and type of the pair.

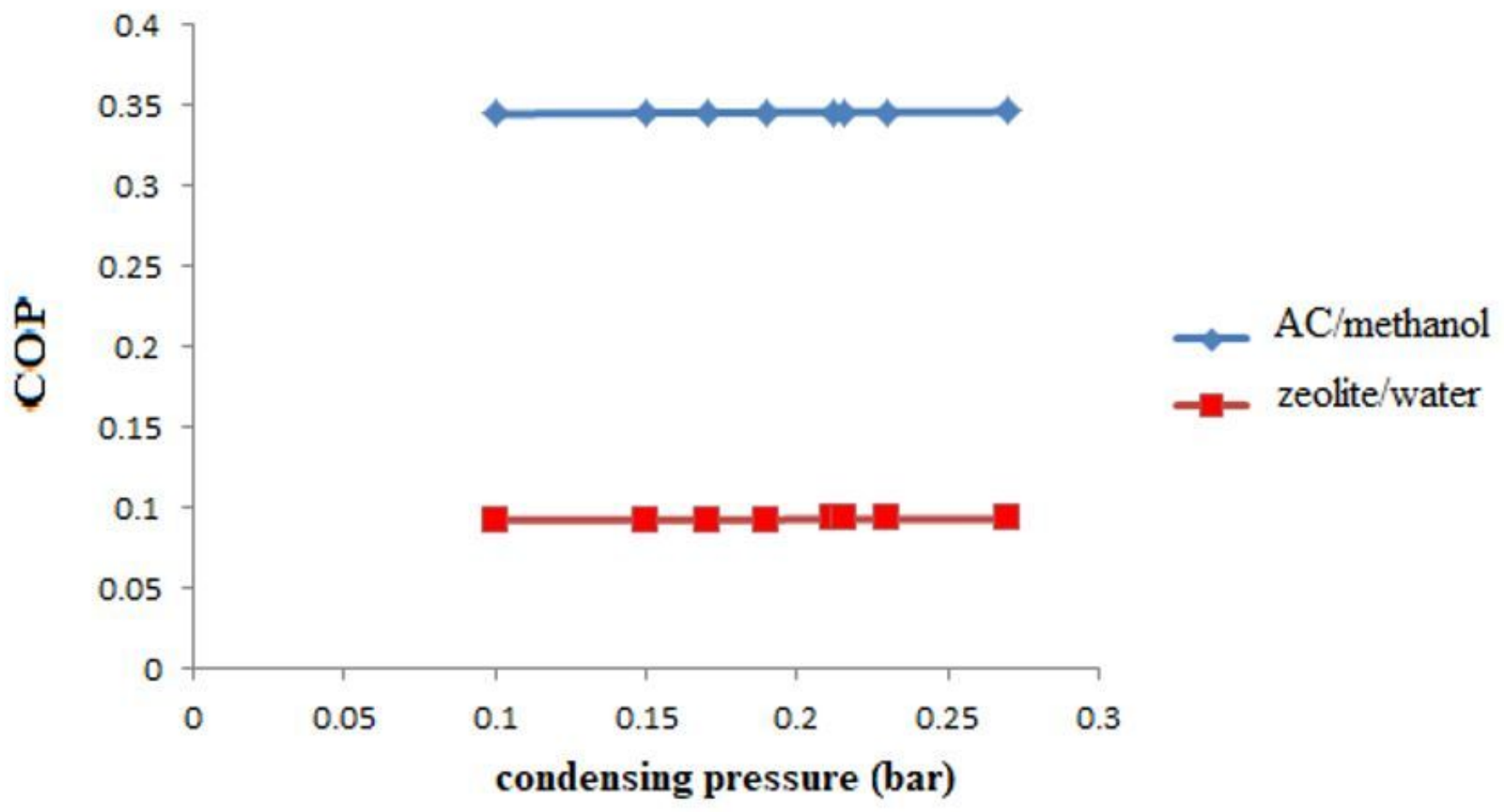

Figure 6 
Effect of condensing pressure $\mathrm{Pc}$ and the pair type on the COP. 